ARTICLE

Received 21 Mar 2014 | Accepted 13 Jun 2014 | Published 15 Jul 2014

DOI: $10.1038 /$ ncomms5395

OPEN

\title{
Impact of residues remote from the catalytic centre on enzyme catalysis of copper nitrite reductase
}

Nicole G. H. Leferink ${ }^{1}{ }^{\star}$, Svetlana V. Antonyuk ${ }^{2, \star}$, Joseline A. Houwman ${ }^{1}$, Nigel S. Scrutton ${ }^{1}$, Robert R. Eady ${ }^{2}$ \& S. Samar Hasnain ${ }^{2}$

Enzyme mechanisms are often probed by structure-informed point mutations and measurement of their effects on enzymatic properties to test mechanistic hypotheses. In many cases, the challenge is to report on complex, often inter-linked elements of catalysis. Evidence for long-range effects on enzyme mechanism resulting from mutations remains sparse, limiting the design/redesign of synthetic catalysts in a predictable way. Here we show that improving the accessibility of the active site pocket of copper nitrite reductase by mutation of a surface-exposed phenylalanine residue (Phe306), located $12 \AA$ away from the catalytic site type-2 $\mathrm{Cu}(\mathrm{T} 2 \mathrm{Cu}$ ), profoundly affects intra-molecular electron transfer, substrate-binding and catalytic activity. Structures and kinetic studies provide an explanation for the lower affinity for the substrate and the alteration of the rate-limiting step in the reaction. Our results demonstrate that distant residues remote from the active site can have marked effects on enzyme catalysis, by driving mechanistic change through relatively minor structural perturbations.

\footnotetext{
${ }^{1}$ Manchester Institute of Biotechnology, Faculty of Life Sciences, University of Manchester, Manchester M1 7DN, UK. ${ }^{2}$ Molecular Biophysics Group, Institute of Integrative Biology, Faculty of Health and Life Sciences, Institute of Integrative Biology, University of Liverpool, Liverpool L69 7ZB, UK. * These authors contributed equally to this work. Correspondence and requests for materials should be addressed to S.S.H., (email: s.s.hasnain@liverpool.ac.uk).
} 
E nzyme catalysis of chemical reactions occur with high specificity and rates required by the biological process ${ }^{1,2}$. How these reactions are controlled and regulated ${ }^{3-5}$ has remained a major challenge to reproduce in synthetic enzymes as very often the focus has been on the catalytic core. The predictability of a mutation in a natural enzyme on enzymatic properties has improved tremendously over the last 20 years through the availability of high-resolution structural studies combined with enzymatic data. Despite this progress, our ability to predict essential structural elements of an enzyme for catalysis remains insufficiently advanced to be able to design/redesign a biological catalyst.

Copper-containing nitrite reductases (CuNiRs) catalyse the one-electron reduction of nitrite to nitric oxide: $\mathrm{NO}_{2}^{-}+2 \mathrm{H}^{+}$ $+\mathrm{e}^{-} \leftrightarrows \mathrm{NO}+\mathrm{H}_{2} \mathrm{O}$, a step in the microbial ATP-generating respiratory dentrification pathway ${ }^{3,4}$. It has recently been shown that protons, in addition to being a substrate in this reaction, are involved in controlling the rate of electron transfer (ET) between the type-1 $\mathrm{Cu}(\mathrm{T} 1 \mathrm{Cu})$ centre and the catalytic type-2 $\mathrm{Cu}(\mathrm{T} 2 \mathrm{Cu})$ centre of the enzyme ${ }^{5-9}$.

In common with many enzymes, targeted mutagenesis and extensive crystallographic studies of the CuNiR family have been powerful approaches to complement kinetic and theoretical studies to understand mechanism and function ${ }^{10-14}$. CuNiRs are trimeric and each monomer has two characteristic $\beta$-sandwich cupredoxin domains that contain a T1Cu centre with (Cys-Met$\mathrm{His}_{2}$ ) ligation. The active site is a T2Cu with $\left(\mathrm{His}_{3}-\mathrm{H}_{2} \mathrm{O}\right)$ ligation, which is situated at the interface between two adjacent monomers in a cleft $\sim 12 \AA$ from the protein surface. Electrons produced during denitrification are donated to the $\mathrm{T} 1 \mathrm{Cu}$ site by a partner redox protein ${ }^{15}$ and subsequently transferred via a $12.6-\AA$ HisCys bridge to the $\mathrm{T} 2 \mathrm{Cu}$ centre in a proton-gated reaction ${ }^{5,7}$. Access to the $\mathrm{T} 2 \mathrm{Cu}$ centre is by way of a $\sim 6$ - $\AA$-wide hydrophobic channel formed by residues from adjacent monomers of the trimer. The active site pocket around the $\mathrm{T} 2 \mathrm{Cu}$ centre has an Asp and a His residue conserved in all CuNiRs. These residues are essential for effective catalysis and are proposed to act in acid base catalysis to provide the two protons required for nitrite reduction ${ }^{16-18}$, and the rate-limiting catalytic step involves a single protonation event kinetically linked to $\mathrm{ET}^{5}$. In the oxidized enzyme as isolated, the Asp residue is hydrogen bonded to a water molecule bound to the T2Cu. This liganded water at the $\mathrm{T} 2 \mathrm{Cu}$ is displaced when nitrite binds. Reduction of the $\mathrm{T} 2 \mathrm{Cu}$ in the absence of nitrite can result in dissociation of this water to form a three coordinate site incapable of binding substrate $^{14,19}$. Inactivation is prevented if nitrite displaces water from the reduced $\mathrm{T} 2 \mathrm{Cu}$ before it can dissociate. Thus, during enzyme turnover in the presence of excess reductant, the delivery of electrons to the active site has to be finely tuned to the availability and binding of substrate.

Altering access from bulk solvent to a buried catalytic centre by substituting residues within the access channel has been shown to change the reaction mechanism. Here we show that substitution of a surface residue (F306C) at the entrance of the channel of $\mathrm{CuNiR}$ results in an altered second sphere coordination of the active site $\mathrm{Cu}$. This changes the rate-limiting step resulting in an increase in inter-molecular ET and catalytic activity despite a significantly lower affinity for substrate.

\section{Results}

Structure of the mutant and its substrate-bound form. We mutated Phe306, a surface residue at the mouth of the proton/ substrate access channel of $A x \mathrm{CuNiR}$, determined its crystallographic structure and used laser-flash photo-excitation methods to rapidly transfer electrons to the $\mathrm{T} 1 \mathrm{Cu}$ site to measure rates of intra-molecular ET, the activity profile and the nitrite concentration dependence of these processes.

Comparison of the crystallographic structures of the 'as isolated' (1.7 ̊ resolution) and substrate bound $(1.75 \AA$ resolution), (Table 1) allowed us to assess the effect of this substitution on the substrate access channel and its associated water network. The global structure of the F306C enzyme was very similar to the wild-type $A x \mathrm{NiR}(2 \mathrm{vw} 4)$ (ref. 10) with an average $\mathrm{C}_{\alpha}$ atom root mean squared deviation of $0.20 \AA$ and maximum displacement $1.5 \AA$ in the $\mathrm{N}$ terminus region. The details of the substrate access channel and comparison with wild type is shown in Fig. 1a,b. The substitution did not change the highly ordered hydrogen bonded water network (Asp92-water-water-Ala131-Asn90Asn107) from the $\mathrm{T} 2 \mathrm{Cu}$ site to the protein surface ${ }^{20}$ that provides the major route of proton delivery to the active site. A notable feature of the channel was the presence of an additional water molecule hydrogen bonded to the liganded water of the $\mathrm{T} 2 \mathrm{Cu}$ ion. This second water molecule has no counterpart in the numerous structures of other two domain CuNiRs, and presents an altered energy landscape for nitrite displacement of the $\mathrm{Cu}$-coordinated water molecule during catalysis. Access to the active site from bulk solvent was also improved, as illustrated by the ability of nitrite to diffuse into the T2Cu active site in the crystal despite polyethylene glycol molecule (PEG) (present as a component of the crystallization medium) being bound across the mouth of the substrate channel. Previously, we have shown that the T2 site is not accessible to nitrite in crystals of wild-type $A x \mathrm{NiR}$ where PEG effectively blocks the channel ${ }^{10}$. Although there is some variation in the positioning of nitrite at the T2 site in CuNiRs, our structure shows that nitrite is bound in a similar mode to wild-type $A x \mathrm{NiR}$ ( $2 \mathrm{xwz}$ ) (ref. 7). The details of nitrite binding are shown in Fig. 2. The space generated by the F306C mutation also allows an adjacent surface residue at the mouth of the channel, Met135, to adopt a dual conformation. The binding of nitrite to the T2Cu results in Met135 adopting largely an 'open' conformation across the substrate access channel, suggesting a communication linkage between the substrate-bound $\mathrm{T} 2 \mathrm{Cu}$ and the distant Met135 (Fig. 2). In fact, this change has been observed in the wild-type $A x \mathrm{NiR}$ enzyme and several other CuNiRs upon nitrite binding but its significance had remained unnoticed. The sensor loop ${ }^{10}$ (His94-Asp92-His89) that reports the status of the $\mathrm{T} 2 \mathrm{Cu}$ site to the electron-donating $\mathrm{T} 1 \mathrm{Cu}$ site remains unaltered. An example of a stereo electron density involving His94-Asp92 is shown in Fig. 3.

Catalytic activity of the mutant. Steady-state nitrite reductase activity of F306C was measured by NO formation by using our recently developed assay ${ }^{5}$ that removes potential ambiguity arising from the reversibility of $\mathrm{NiR}$, and also the side reaction of the reduction of the product $\mathrm{NO}$ in the bulk solvent to form $\mathrm{N}_{2} \mathrm{O}$. Both wild-type $A x \mathrm{NiR}$ and the F306C variant followed normal Michaelis-Menten kinetics with nitrite concentrations up to $50 \mathrm{mM}$, suggestive of a single site of nitrite binding. However, the substitution of F306 resulted in an approximately fourfold increase in specific activity and had a marked effect on the apparent $K_{\mathrm{M}}$ for nitrite, which with a value of $1.2 \pm 0.1 \mathrm{mM}$ is some 50 -fold weaker than for wild-type $A x \mathrm{NiR}$. Kinetic parameters are summarized in Table 2. Since the structure shows access to the substrate channel is enhanced, the weaker apparent affinity for nitrite may arise from the presence of the additional water in the second coordination sphere of the $\mathrm{T} 2 \mathrm{Cu}$ stabilizing the coordinated water that nitrite needs to displace in order to bind. An additional contributing feature revealed by the structure is the positioning of the gatekeeper Asp92 residue in the 'closed' conformation ${ }^{11}$ that may result in a slower escape of NO 


\section{Table 1 | Data collection and refinement statistics ${ }^{\star}$.}

F306C

\begin{tabular}{l}
\hline Data collection \\
Space group \\
Cell dimensions \\
$a, b, c(\AA)$ \\
$\alpha, \beta, \gamma\left({ }^{\circ}\right)$ \\
Resolution $(\AA)$ \\
$R_{\text {merge }}$ \\
$I / \sigma l$ \\
Completeness (\%) \\
Redundancy
\end{tabular}

Refinement

Resolution ( $\AA$ )

No. of reflections

$R_{\text {work }} / R_{\text {free }}$

No. of atoms

Protein

Ligand/ion

Water

B-factors

Protein

$\mathrm{Cu}$

$\mathrm{Zn}$

MES

$\mathrm{NO}_{2}$

PEG

Water

R.m.s.d.

Bond lengths ( $\AA$ )

Bond angles $\left({ }^{\circ}\right)$

PDB access codes
R3

$$
\begin{gathered}
89.9,89.9,289.5 \\
90,90,120 \\
50-1.69(1.79-1.69) \\
7.0(80.0) \\
11(2) \\
100(99) \\
5(5)
\end{gathered}
$$

46.5-1.7

97,508

18.7 (22.4)

5,850

5,074

36

740

24.6

20

30

47

35.2

0.015

1.616
$\mathrm{F306C}+\mathrm{NO}_{\mathbf{2}}$

R3

$89.6,89.6,144.0$

$90,90,120$

40-1.75 (1.84-1.75)

$8.6(66.8)$

$10(2)$

$99.9(100.0)$

4.5 (4.5)

40-1.75

43,456

17.9 (21.0)

2,959

2,617

19

323

28.64

23.5

41

40

54

37.8

0.012

1.542

$4 \operatorname{csz}$
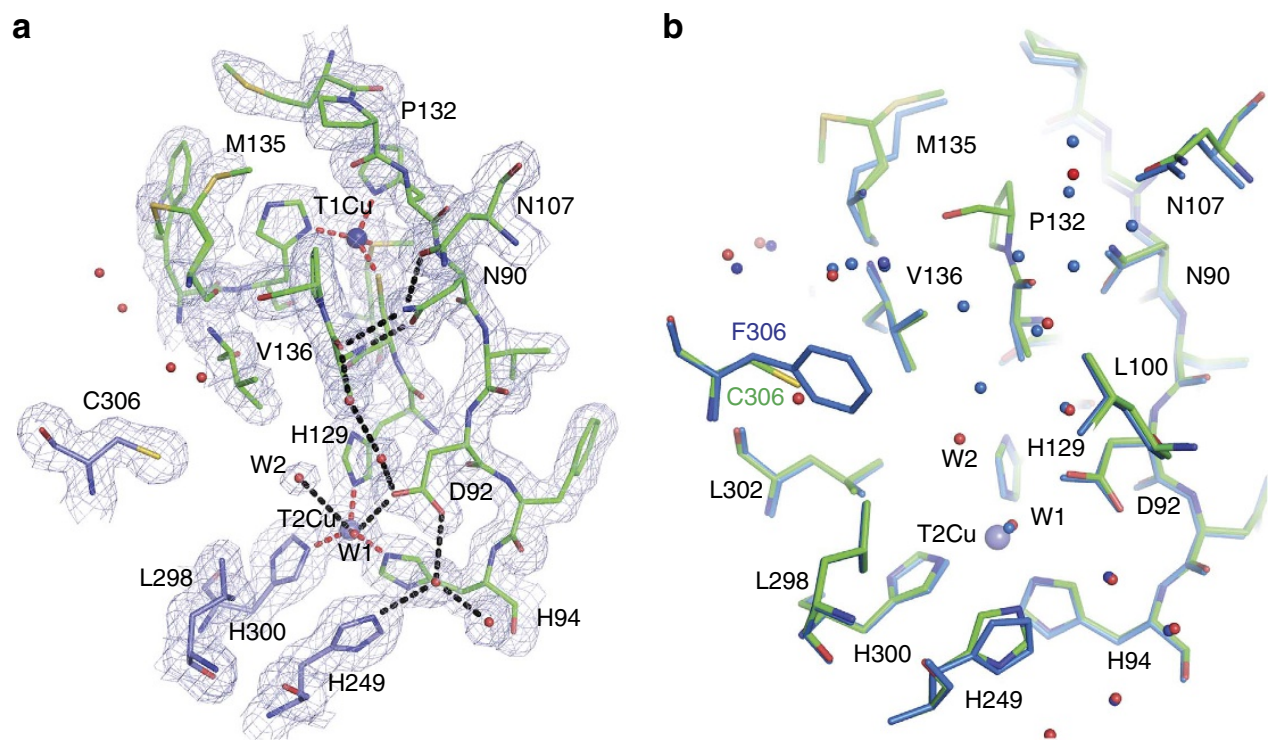

Figure 1 | Comparison of the main proton channel network in as-isolated F306C mutant and wild-type AxNiR. (a) The main proton channel of $F 306 C$ has an additional water molecule, W2, that forms an hydrogen bond with the liganded water of the T2Cu ion. The $2 F_{\mathrm{o}}-F_{\mathrm{c}}$ electron density map for $\mathrm{F} 306 \mathrm{C}$ mutant contoured at the $1 \sigma$ level. Distances from $\mathrm{Cu}$ atoms to coordinating protein atoms are shown as dotted red lines. Hydrogen bonds are shown in black dotted lines. Water molecules are shown as red spheres and $\mathrm{Cu}$ atoms as blue spheres. Residues are colour coded according to their chain. (b) Comparison between wild-type AxNiR (blue) and F306C mutant (green). Water molecules for the mutant are shown in red, whereas for wild-type protein in blue. 
a

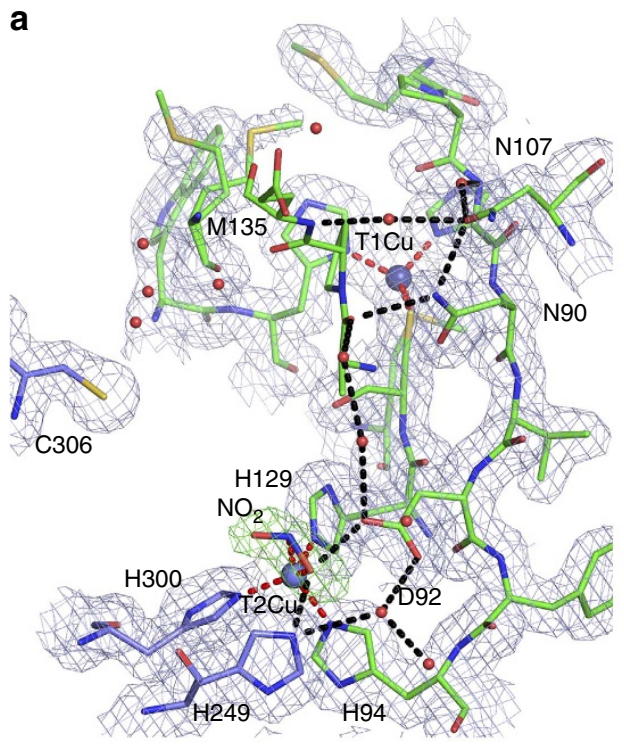

b

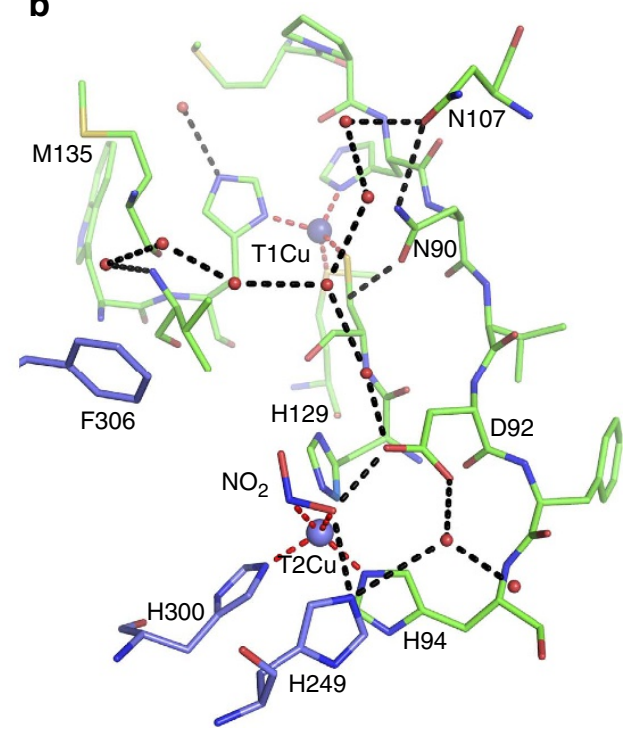

Figure 2 | Comparison of the nitrite-binding mode in as isolated $\mathbf{F 3 0 6 C}$ mutant and wild-type AxNiR. $2 F_{\mathrm{o}}-F_{\mathrm{c}}$ electron density maps contoured at $1 \sigma$ level for both (a) as-isolated F306C mutant and (b) wild-type AxNiR. The Cu sites are shown as blue spheres with coordination bonds shown as dashed red lines. Important hydrogen bonds are shown as dashed black lines. $1 F_{\mathrm{o}}-F_{\mathrm{c}}$ omit map for nitrite is shown in green at $4 \sigma$ level. Note that crystals of $F 306 \mathrm{C}$ were grown in the presence of PEG that prevents nitrite diffusion into crystals of wild-type $\mathrm{AxNiR}^{10}$, consistent with the mutation resulting in enhanced access to the active site.

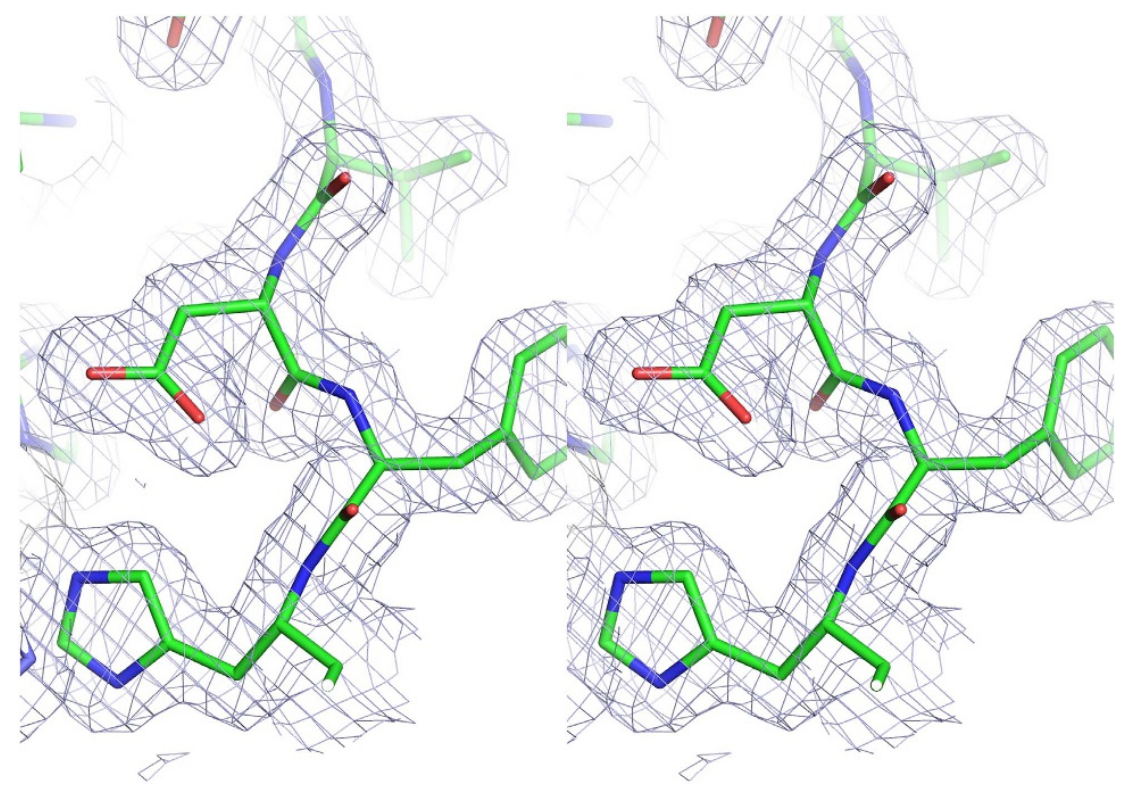

Figure 3 | A stereo picture of the $\mathbf{2} \mathbf{F}_{\mathbf{o}}-\mathbf{F}_{\mathbf{c}}$ electron density map. Electron density at $1 \sigma$ level around His 94 , Phe93 and Asp92 for the structure of the resting state of F306C mutant.

Table 2 | Steady-state kinetic parameters of F306C compared with wild-type AxNiR.

\begin{tabular}{lccr} 
& $\boldsymbol{k}_{\text {cat }}\left(\mathbf{s}^{-\mathbf{1}}\right)$ & $\boldsymbol{K}_{\mathbf{M}} \mathbf{N O}_{\mathbf{2}}^{-} \mathbf{( m M )}$ & $\boldsymbol{k}_{\text {cat }} / \boldsymbol{K}_{\mathbf{M}}\left(\mathbf{m} \mathbf{M}^{-\mathbf{1}} \mathbf{s}^{-\mathbf{1}}\right)$ \\
\hline Wild-type AxNiR* & $89 \pm 3$ & $0.027 \pm 0.005$ & 3,300 \\
F306C & $310 \pm 10$ & $1.2 \pm 0.1$ & 260
\end{tabular}

$\mathrm{NO}_{2}$, nitrite.

${ }^{\star}$ Data obtained from ref. 7. Values shown are the mean \pm s.d. of two individual experiments. The apparent kinetic constants for both the wild-type and F306C summarized here were obtained by nonlinear fitting of the data. 
from the active site pocket, resulting in a weaker apparent $K_{\mathrm{M}}$ value for nitrite due to competitive binding of $\mathrm{NO}$ to $\mathrm{T} 2 \mathrm{Cu}$ in the micro-reversibility of $\mathrm{NiR}$ function.

The kinetics of inter-Cu ET from T1Cu to T2Cu was measured by using laser-flash photo-excitation methods to rapidly transfer electrons to the $\mathrm{T} 1 \mathrm{Cu}$ site as described previously, ${ }^{5,6}$ (Fig. 4). Following the initial rapid reduction of $\mathrm{T} 1 \mathrm{Cu}$, an electron redistributes between the two $\mathrm{Cu}$ centres as the thermodynamic redox equilibrium is re-established. The effect of the F306C substitution was to slow this ET reaction from $370 \mathrm{~s}^{-1}$, seen in wild-type $A x \mathrm{NiR}^{5}$, to $\sim 170 \mathrm{~s}^{-1}$. Since there is no significant change to the redox potentials of the $\mathrm{Cu}$ centres at this $\mathrm{pH}$ (Table 3) the slower rate most likely arises from an increase in reorganizational energy associated with the altered water structure of the $\mathrm{T} 2 \mathrm{Cu}$ sites.

Several pulse radiolysis ${ }^{16,21,22}$, protein-film voltammetry ${ }^{9,19}$ and laser-flash-photolysis studies ${ }^{5,7}$ of different CuNiRs have shown that during single turnover experiments, the rate of inter$\mathrm{Cu}$ ET is decreased by the presence of nitrite. The degree of inhibition is $\mathrm{pH}$-dependent and for wild-type $A x \mathrm{NiR}$ at $\mathrm{pH} 7$ the $k_{\text {obs }}$ decreases from 370 to $\sim 250 \mathrm{~s}^{-1}$ at saturating nitrite concentrations $s^{5,7}$. The effect of nitrite in inhibiting the rate of ET has been suggested to arise from conformational and midpoint potential changes of the $\mathrm{T} 2 \mathrm{Cu}$ centre on replacement of water by nitrite ${ }^{23}$. This seems counter-intuitive to the observed rise in the $E_{\mathrm{m}}$ of the $\mathrm{T} 2 \mathrm{Cu}$ centre on binding nitrite, thus increasing the driving force for ET, and more likely is due to a

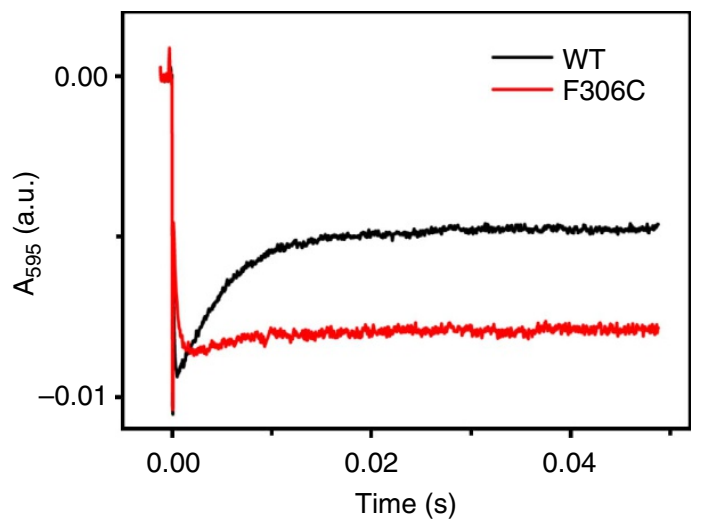

Figure 4 | Time-resolved absorbance changes upon laser excitation at pH $\mathbf{5 . 8}$ in the absence of nitrite. Absorbance changes at $595 \mathrm{~nm}$ observed in the laser flash-photolysis instrument during reduction of wild-type (WT) AxNiR (black) and F306C (red) with $\mathrm{NADH}\left(\lambda_{\text {exc }}=355 \mathrm{~nm}\right)$. Experiments were carried out in the absence of nitrite in $\mathrm{MMH}$ buffer, $\mathrm{pH}$ 5.8, containing $30 \mu \mathrm{M}$ WT AxNiR or F306C, NiR, $200 \mu \mathrm{M}$ NADH and $50 \mathrm{mM}$ mediator at $4{ }^{\circ} \mathrm{C}$. Traces shown are the average of 3-6 individual traces and were fitted by using a double-exponential equation. Observed rates of inter-Cu ET for WT AxNiR and F306C are 200 and $160 \mathrm{~s}^{-1}$, respectively. The lower absorbance at equilibrium observed for $\mathrm{F} 306 \mathrm{C}$ is consistent with an $\sim 60 \mathrm{mV}$ decrease in the $E_{\mathrm{m}}$ of the T2Cu centre. rate-limiting proton-gating event associated with catalysis. The nitrite concentration dependence of the inhibition of ET showed an initial inhibition followed by an increase at higher concentrations. This has been attributed ${ }^{5,7}$ to binding at two sites with different affinities or complexities arising from reaction branching associated with the random sequential mechanism for NiR function ${ }^{5,23}$. Whatever the origin of this complex behaviour, the different substrate dependences of internal ET and the steadystate activity show that inter-Cu ET cannot be rate limiting in wild-type $A x \mathrm{NiR}$ at $\mathrm{pH} 7$.

Effect of nitrite concentration on the rate of ET. A marked difference in behaviour of F306C was observed in the effect of nitrite concentration on the rate of ET. Although starting from a lower value under non-turnover conditions, inter-Cu ET was not inhibited by nitrite but stimulated, showing a 'normal' hyperbolic saturation dependence, in contrast to the complex behaviour of the wild-type enzyme (Fig. 5a,b). At saturating nitrite concentrations, the $k_{\text {obs }}$ of $\sim 920 \mathrm{~s}^{-1}$ was some fourfold faster than for wild-type $A x \mathrm{NiR}^{5}$, and is associated with an approximately fourfold increase in enzymatic activity. The apparent affinity for nitrite obtained from the laser flashphotolysis data $\left(K_{\mathrm{s}}=0.8 \pm 0.1 \mathrm{mM}\right)$ is in the same range as the apparent $K_{\mathrm{M}}$ value obtained from the steady-state activity $\left(K_{\mathrm{M}}=1.2 \pm 0.1 \mathrm{mM}\right)$. These data, together with the similar patterns of nitrite dependence of activity in steady-state assays and inter-Cu ET, clearly show that ET has now become the ratelimiting step in turnover of $\mathrm{F} 306 \mathrm{C}$ at $\mathrm{pH} 7$, and results in a single site of nitrite binding.

These changes are not due to an effect on the midpoint potentials since the difference in redox potential between the $\mathrm{T} 1 \mathrm{Cu}$ and $\mathrm{T} 2 \mathrm{Cu}$ centres provides little driving force for ET at pH 7 or 5.8 (Table 3). It most likely arises from perturbation of a protonation event coupled to substrate reduction rather than inter- $\mathrm{Cu} \mathrm{ET}$, since in the absence of nitrite this is slower in the mutant. Recent computational data indicate that in CuNiRs, ET is triggered by the increase in potential of the reduced T2 site when nitrite binds, gated by the protonation of the conserved Asp residue in the active site pocket ${ }^{6}$. The $\mathrm{pH}$ dependence of ET in the absence of nitrite reveals that the $\mathrm{F} 306 \mathrm{C}$ mutation abolishes proton gating (Fig. 4). The rates observed at $\mathrm{pH} 5.8$ and 7 are almost identical in F306C, 160 and $170 \mathrm{~s}^{-1}$ respectively, compared with a significantly slower inter-Cu ET at $\mathrm{pH} 5.8$ relative to $\mathrm{pH} 7$ for wild-type $A x \mathrm{NiR}, 200$ and $370 \mathrm{~s}^{-1}$, respectively (Table 4 ). This is confirmed by the altered $\mathrm{pH}$ profile of the activity of the mutant, which shows optimal activity at $\mathrm{pH} \sim 6.7$, and a somewhat broader maximum than the wild-type enzyme, which shows maximal activity at $\mathrm{pH}$ $\sim 6.5$ (Fig. 6).

\section{Discussion}

We have shown previously that perturbation of the main proton channel in the N90S substitution of $A x \mathrm{NiR}$ has a similar effect on the nitrite concentration dependence of ET to the F306C

Table 3 | Reduction potentials for T1Cu and T2Cu centres in wild-type AxNiR and F306C.

\begin{tabular}{lccc} 
& T1Cu (mV) & T2Cu (mV) & T2Cu (mV) \\
pH 5.8 & 7 & $260 \pm 15$ \\
WT AxNiR & & $244 \pm 18^{\star}$ & $210 \pm 15$ \\
F306C & $255 \pm 3^{\star}$ & $269 \pm 10$ & $262 \pm 3$ \\
\hline
\end{tabular}

$\mathrm{NO}_{2}$, nitrite; r.m.s.d., root mean square deviation; T1Cu, type-1 Cu; T2Cu, type-2 Cu; WT, wild type.

${ }^{*}$ Values are taken from ref. 7. Values shown for $\mathrm{T} 1 \mathrm{Cu}$ and $\mathrm{T} 2 \mathrm{Cu}$ at $\mathrm{pH} 7$ are obtained after fitting the data sets from a single experiment to the Nernst equation. Since the $\mathrm{T} 1 \mathrm{Cu}$ reduction potential is $\mathrm{pH}$ independent ${ }^{16}$, the values for $\mathrm{T} 2 \mathrm{Cu}$ at pH 5.8 were calculated from the relative absorbance recovery in the flash-photolysis experiments performed at $\mathrm{pH} 5.8$. 
a

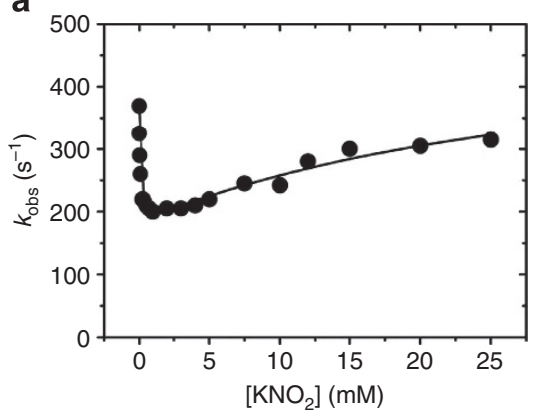

b

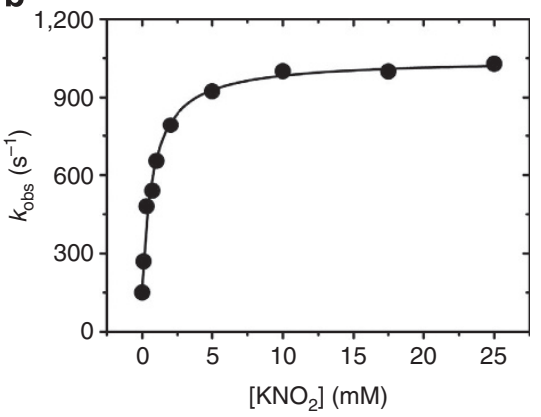

Figure 5 | Substrate dependence of inter-Cu ET in laser photo-excitation experiments. Wild-type AxNiR (a) and F306C (b). All experiments were carried out in $50 \mathrm{mM}$ potassium phosphate buffer, $\mathrm{pH} 7.0$, at $4{ }^{\circ} \mathrm{C}$. The solid line in a represents a fit of the data obtained for wild-type $A x N i R$ to an equation reflecting two substrate-binding sites, and in $\mathbf{b}$ a fit of the data obtained for $\mathrm{F} 306 \mathrm{C}$ to a hyperbolic one-site binding equation. The data shown in $\mathbf{a}$ contains re-plotted data from ref. 5.

\begin{tabular}{|c|c|c|}
\hline & pH $7.0\left(\mathrm{~s}^{-1}\right)$ & pH $5.8\left(s^{-1}\right)$ \\
\hline WT AxNiR & $370^{\star}$ & 200 \\
\hline F306C & 170 & 160 \\
\hline
\end{tabular}

WT, wild type

${ }^{*}$ Value are taken from ref. ${ }^{5}$. Values obtained are an average of 3-6 shots.

substitution ${ }^{7}$. However, although an additional water molecule was present in the substrate access channel, it was not hydrogen bonded to the coordinated water at the T2Cu site. The effects of surface residue substitution, F306, described here produce sufficient flexibility to allow increased solvent/ substrate access, illustrated by the presence of a second water molecule (W2) in the active site pocket and also improved access to nitrite since binding is not prevented by PEG bound at the channel's entrance. Because access of both water and nitrite is enhanced, we attribute the 50 -fold increase in apparent $K_{\mathrm{M}}$ for nitrite not to there being more water to compete with, but rather arising from stabilization of the ligated water owing to its hydrogen bonding to W2, making it more difficult for nitrite to displace. In native CuNiR, access of water to the active site pocket is not limited by surface residues blocking the channel but rather by steric hindrance provided by an isoleucine residue shielding the active site $^{24}$. Several computational studies have shown the importance of second sphere ligands in modulating the energy landscape of the T2Cu site, specifically the effect of the position and protonation state of the ligated water molecule ${ }^{25}$.

The decrease in catalytic efficiency $\left(k_{\mathrm{cat}} / K_{\mathrm{M}}\right)$ shows the importance of a bulky residue at the surface of the substrate channel in restricting solvent access to the active site pocket in the native enzyme. The overall tight regulation of the reaction chemistry in terms of coordinated electron and proton supply to, and nitrite availability at, the active site of CuNiRs prevents the formation of a deactivated enzyme species through premature reduction of $\mathrm{T} 2 \mathrm{Cu}$ leading to loss of the coordinated water ligand. It is clear that this fine-tuning of the reaction chemistry extends to surface residues remote from the active site. This result has wider implications to the predictive aspects of design/redesign of synthetic biological catalysts that are of central importance to industrial biocatalysis.

\section{Methods}

Cloning and mutagenesis. The nirA gene from Alcaligenes xylosoxidans (AxNiR) was re-cloned for cytoplasmic expression to improve expression levels. NirA without its periplasmic signal peptide was PCR amplified from a vector containing the wild-type nirA gene ${ }^{26}$ by using the oligonucleotide primers $A x \mathrm{NiR}$ SPfw (5'-CCCGTCTCCCATGCAGGACGCCGACAAGC- $\left.3^{\prime}\right), A x$ NiR_rv ( $5^{\prime}$-GG AAGCTTTCAGCGCGGAATCGGC-3') (restriction sites are underlined and changed nucleotides are in bold), and cloned between the NcoI and HindIII restriction sites of the pET28a vector (Novagen, San Diego, CA, USA), resulting in the plasmid pET-AxNiR-SP. Site-directed mutagenesis to generate F306C was performed by using $\mathrm{pET}-A x \mathrm{NiR}-\mathrm{SP}$ as template and using the oligonucleotide primers F306C_fw ( $5^{\prime}$-CCACAACCTGATCGAGGCCTGCGAACTGGGCGC GGCCGGCCAC- $\left.3^{\prime}\right)$ and F306C_rv (5'-GTGGCCGGCCGCGCCCAGTTCGCAG GCCTCGATCAGGTTGTGG-3') according to the QuikChange protocol (Stratagene, La Jolla, CA, USA). Mutagenesis was confirmed by automated sequencing (Eurofins MWG Operon, London, UK).

Protein expression and purification. Escherichia coli BL21(DE3) cells harbouring a pET-AxNiR-SP plasmid were grown in 1 litre cultures of Luria-Bertani medium supplemented with $50 \mu \mathrm{g} \mathrm{ml}^{-1}$ kanamycin at $37^{\circ} \mathrm{C}$ until an $\mathrm{OD}_{600}$ of $\sim 0.6$ was reached. Protein expression was induced by the addition of $0.5 \mathrm{mM}$ (isopropyl-D1-thiogalactopyranoside) IPTG and $1 \mathrm{mM} \mathrm{CuSO}_{4}$. Incubation was continued for $16 \mathrm{~h}$ before harvesting by centrifugation. The cell pellet was re-suspended in $20 \mathrm{mM}$ MES, $\mathrm{pH}$ 6.0, and the cells were broken by ultra-sonication. The lysate was cleared by centrifugation and dialysed against $20 \mathrm{mM} \mathrm{MES}$ and $1 \mathrm{mM} \mathrm{CuSO}_{4}, \mathrm{pH} 6.0$, to restore the $\mathrm{Cu}$ content of the $\mathrm{T} 2 \mathrm{Cu}$ centre. This was followed by further dialysis against deionized water $\left(\mathrm{dH}_{2} \mathrm{O}\right)$. The cell extract was then applied onto a carboxymethyl-cellulose (Whatman, Kent, UK) column equilibrated with $\mathrm{dH}_{2} \mathrm{O}$. The column was washed with 10 column volumes of $\mathrm{dH}_{2} \mathrm{O}, 10$ column volumes of $40 \mathrm{mM}$ MES, pH 6.0, and 10 column volumes of $40 \mathrm{mM}$ MES and $50 \mathrm{mM} \mathrm{NaCl}, \mathrm{pH}$ 6.0. The protein was eluted with $300 \mathrm{mM} \mathrm{NaCl}$ in $40 \mathrm{mM} \mathrm{MES}, \mathrm{pH}$ 6.0, and stored at $-80^{\circ} \mathrm{C}$ in $20 \mathrm{mM}$ Tris, $\mathrm{pH} 7.4$, until further use. AxNiR concentrations were determined by using an extinction coefficient of $\epsilon_{595}=6.3 \mathrm{mM}^{-1} \mathrm{~cm}^{-1}$ for both the wild-type enzyme as well as F306C.

Structure determination. Crystals for the $\mathrm{F} 306 \mathrm{C}$ and $\mathrm{F} 306 \mathrm{C}+\mathrm{NO}_{2}^{-}$structures of $A x \mathrm{NiR}$ were grown by using the hanging drop vapour diffusion method at room temperature. Protein solution, $2 \mu \mathrm{l}$ of $10 \mathrm{mg} \mathrm{ml}^{-1}$, in $20 \mathrm{mM}$ Tris- $\mathrm{HCl}(\mathrm{pH} \mathrm{7.4)}$ was mixed with an equal volume of reservoir solution containing 15\% PEG550 MME, $50 \mathrm{mM} \mathrm{ZnSO}_{4}$, and $50 \mathrm{mM}$ MES buffer (pH 6.5). Crystals grew within 2 days. Before being frozen in liquid nitrogen crystals were transferred into 30\% PEG550 MME, $50 \mathrm{mM} \mathrm{ZnSO}_{4}$ and $100 \mathrm{mM}$ MES buffer, $\mathrm{pH} \mathrm{6.5,} \mathrm{for} 10 \mathrm{~s}$ nitrite-bound $\mathrm{F} 306 \mathrm{C}$ was obtained by soaking crystals in $200 \mathrm{mM} \mathrm{NaNO}_{2}^{-}, 20 \%$ PEG550 MME, $50 \mathrm{mM}$ $\mathrm{ZnSO}_{4}$ and $50 \mathrm{mM}$ MES buffer for $15 \mathrm{~min}$ before flash cooling in $200 \mathrm{mM} \mathrm{NaNO}_{2}^{-}$, 25\% PEG550 MME, $50 \mathrm{mM} \mathrm{ZnSO}_{4}$ and $50 \mathrm{mM}$ MES buffer. Crystallographic data were collected on Soleil beamline PROXIMA1 by using a PILATUS-6M detector to $1.69 \AA$ A resolution for F306C, and on DIAMOND's microfocus beamline ID-24 to $1.75 \mathrm{~A}$ resolution for the $\mathrm{F} 306 \mathrm{C}+\mathrm{NO}_{2}^{-}$complex. Data for as-isolated $\mathrm{F} 306$ structure were integrated and scaled by using $\mathrm{XDS}^{27}$. Data for $\mathrm{F} 306 \mathrm{C}+\mathrm{NO}_{2}^{-}$complex were integrated in MOSFLM $^{28}$ and scaled by Scala ${ }^{29}$. The structure of mutant was refined starting from isomorphous model of the wild-type structure $(2 \mathrm{vw} 4)$, whereas $\mathrm{F} 306 \mathrm{C}+\mathrm{NO}_{2}^{-}$model was refined starting from isomorphous model $4 \mathrm{csp}$. Both structures were refined by using REFMAC ${ }^{30}$ in the CCP4 (ref. 31) programme suite with isotropic B-factors and hydrogen atoms in riding positions. Rebuilding of the model between refinement cycles and adding water molecules was performed in $\mathrm{Coot}^{32}$. The quality of the models was assessed by using the Molprobity ${ }^{33}$ server. A 

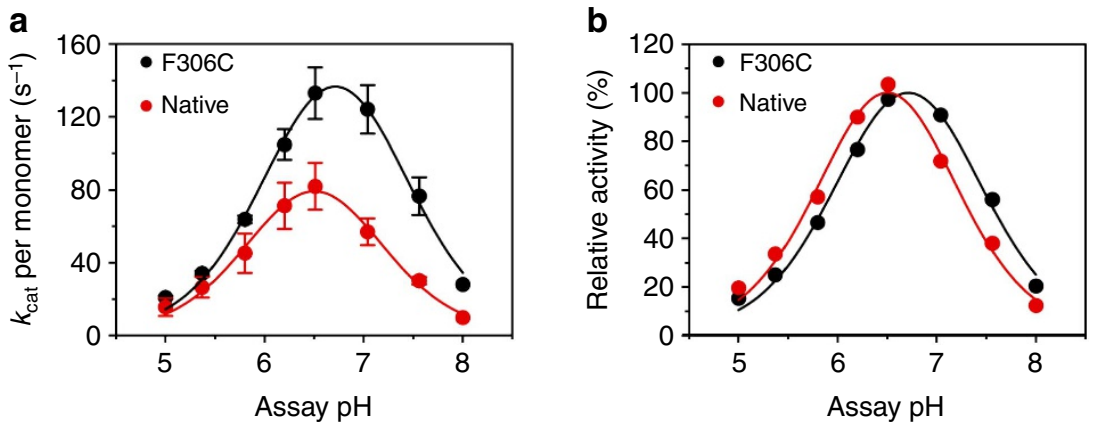

Figure 6 | pH dependence of nitrite reductase activity of F306C compared with wild-type AxNiR. Steady-state activities of NiR activity were measured by using dithionite as electron donor. The oxidation of dithionite was measured spectrophotometrically at $315 \mathrm{~nm}\left(\epsilon_{315}=8.043 \mathrm{mM}^{-1} \mathrm{~cm}^{-1}\right)$ in a stopped-flow apparatus by using $\mathrm{MMH}$ buffer, titrated to the indicated $\mathrm{pH}$, at $4{ }^{\circ} \mathrm{C}$ (refs 5,8 ). Initial rates were determined from five averaged progress curves and corrected for the background depletion of absorbance at $315 \mathrm{~nm}$ in the absence of AxNiR. Data shown are the mean \pm s.d. of two individual experiments. The activity profile for the wild-type enzyme is different from that published by Abraham et al. ${ }^{34}$, which was measured by using a stopped-time assay. The optimum for wild-type $\mathrm{AxNiR}$ found in the current study is $\sim \mathrm{pH} 6.5$, rather than $\mathrm{pH} 5.2$, also no plateau at pH 5.8-6.2 is observed. This 'new' optimum pH is similar to the $\mathrm{pH}$ optimum of 6.2 found for AcNiR and AfNiR. The pH optimum for F306C is slightly shifted to $\mathrm{pH} 6.7$ compared with the wild-type enzyme. (a) Observed rates versus $\mathrm{pH}$, and (b) relative activity versus $\mathrm{pH}$. The $\mathrm{pH}$ dependence of the kinetic parameters were fitted to an equation describing a double ionization ${ }^{35}$. The calculated macroscopic $p K_{a}$ values are 6.0 and 7.0 for wild-type $A x N i R$, and 6.1 and 7.3 for F306C.

summary of diffraction data, refinement statistics and the quality indicators for the structures are given in Table 1.

Kinetic experiments. Protein samples for all kinetic experiments were prepared and handled anaerobically in a glovebox (Belle Technology, Portesham, UK) under a nitrogen atmosphere in which oxygen levels were kept below 5 p.p.m. The steadystate NiR activity was measured in a stopped-flow instrument (Applied Photophysics SC18MV) by using deoxyhemoglobin as NO scavenger ${ }^{5}$. All measurements were carried out in $50 \mathrm{mM}$ potassium phosphate buffer, $\mathrm{pH} 7.0$, at $4{ }^{\circ} \mathrm{C}$.

Absorbance changes were recorded at $430 \mathrm{~nm}$, and initial rates were determined from the slopes of five averaged progress curves and converted to units of activity by dividing through a calibration factor of $0.0162 \Delta \mathrm{A} 430 \mu \mathrm{M}^{-1}$ (ref. 7). The steady-state activities of native $A x \mathrm{NiR}$ and $\mathrm{F} 306 \mathrm{C}$ as a function of $\mathrm{pH}$ were measured by using dithionite as electron donor. The oxidation of dithionite was measured spectrophotometrically at $315 \mathrm{~nm}\left(\epsilon_{315}=8.043 \mathrm{mM}^{-1} \mathrm{~cm}^{-1}\right)$ in the stopped-flow apparatus by using $25 \mathrm{mM}$ MES- $25 \mathrm{mM}$ HEPES- $25 \mathrm{mM}$ maleic acid $(\mathrm{MMH})$, titrated to the indicated $\mathrm{pH}$, at $4{ }^{\circ} \mathrm{C}$ (refs 5,8). Initial rates were determined from five averaged progress curves and corrected for the background depletion of absorbance at $315 \mathrm{~nm}$ in the absence of $A x \mathrm{NiR}$.

Laser flash-photolysis experiments were carried out on solutions containing $30 \mu \mathrm{M} \mathrm{NiR}, 200 \mu \mathrm{M} \mathrm{NADH}$ and $50 \mathrm{mM} \mathrm{N}$-methyl nicotinamide, and when appropriate, various concentrations of $\mathrm{KNO}_{2}^{-}$in $50 \mathrm{mM}$ potassium phosphate buffer, $\mathrm{pH} 7.0$ or $25 \mathrm{mM}$ MMH buffer, $\mathrm{pH} 5.8$. All laser experiments were performed at $4{ }^{\circ} \mathrm{C}$. The samples were excited at $355 \mathrm{~nm}$ by using the third harmonic of a Q-switched Nd:YAG laser (Brilliant B, Quantel). Spectral transients were collected at $595 \mathrm{~nm}$ for up to $50 \mathrm{~ms}$ by using an Applied Photophysics LKS-60 flash-photolysis instrument, and fitted to a double-exponential equation.

Reduction potentials. The reduction potentials of $\mathrm{T} 1 \mathrm{Cu}$ and $\mathrm{T} 2 \mathrm{Cu}$ were deter-

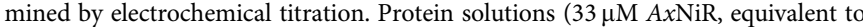
$100 \mu \mathrm{M} \mathrm{T} 2 \mathrm{Cu}$ ) were titrated with sodium dithionite as the reductant. Mediators (phenazine methosulphate $(2 \mu \mathrm{M})$, methyl viologen $(0.5 \mu \mathrm{M})$ and benzyl viologen $(1 \mu \mathrm{M}))$ were added to facilitate electrical communication between enzyme and electrode before titration. The electrode potential was allowed to stabilize between each addition. The optical absorbance at $595 \mathrm{~nm}$ of oxidized $\mathrm{T} 1 \mathrm{Cu}$ was monitored at each potential by using a Cary UV-50 Bio UV-visible scanning spectrophotometer. The electrochemical potential of the solution was measured by using a Thermo Orion ORP electrode at $25^{\circ} \mathrm{C}$. A factor of $210 \mathrm{mV}$ was used to correct values to the standard hydrogen electrode. During the titration with dithionite, samples $(250 \mu \mathrm{l})$ were withdrawn for EPR analysis. The samples were placed in $4 \mathrm{~mm}$ Suprasil quartz EPR tubes (Wilmad LabGlass) and sealed inside the glovebox where they were immediately removed and frozen in liquid nitrogen. Samples were stored in liquid nitrogen to prevent re-oxidation until they were analysed. EPR spectra were recorded at $20 \mathrm{~K}$ on a Bruker EMX X-band EPR spectrometer. The microwave power was $0.5 \mathrm{~mW}$, the modulation frequency $100 \mathrm{kHz}$, and the modulation amplitude $5 \mathrm{G}$. The $\mathrm{T} 1 \mathrm{Cu}$ reduction potentials were determined from the difference in absorbance at $595 \mathrm{~nm}$ between oxidized and reduced $\mathrm{T} 1 \mathrm{Cu}$, and the $\mathrm{T} 2 \mathrm{Cu}$ reduction potentials were determined from the difference in the hyperfine peaks of the EPR spectrum between oxidized and reduced $\mathrm{T} 2 \mathrm{Cu}$. Midpoint potentials were obtained from fitting the data to the Nernst equation.
Because the $\mathrm{T} 1 \mathrm{Cu}$ reduction potential is $\mathrm{pH}$ independent ${ }^{16}$, the reduction potentials for $\mathrm{T} 2 \mathrm{Cu}$ at $\mathrm{pH} 5.8$ were calculated from the relative absorbance recovery observed in the flash-photolysis experiments at $\mathrm{pH} 5.8$ by using the Nernst equation.

\section{References}

1. Kaan, H. Y. K., Hackney, D. D. \& Kozielski, F. The structure of kinesin-1 motor-tail complex reveals the mechanism of autoinhibition. Science 333, 883-885 (2011).

2. Strugatsky, D. et al. Structure of the proton-gated urea channel from the gastric pathogen Heliobacter pylori. Nature 493, 255-258 (2013).

3. Antonyuk, S. V., Cong, H., Eady, R. R. \& Hasnain, S. S. Structures of protein-protein complexes involved in electron transfer. Nature 496, 123-126 (2013).

4. Eady, R. R. \& Hasnain, S. S. in Comprehensive Coordination Chemistry ll Ch 28 Vol. 8 (eds Que, L. \& Tolman, W.) 759-786 (Elsevier, 2003).

5. Brenner, S. et al. Demonstration of proton-coupled electron transfer in the copper-containing nitrite reductases. J. Biol. Chem. 284, 25973-25983 (2009).

6. Ghosh, S., Dey, A., Sun, Y., Scholes, C. P. \& Solomon, E. I. Spectroscopic and computational studies of nitrite reductase: proton induced electron transfer and backbonding contributions to reactivity. J. Am. Chem. Soc. 131, 277-288 (2009).

7. Leferink, N. G. H. et al. Proton-coupled electron transfer in the catalytic cycle of Alcaligenes xylosoxidans copper-dependent nitrite reductase. Biochemistry 50, 4121-4131 (2011).

8. Leferink, N. G. H., Eady, R. R., Hasnain, S. S. \& Scrutton, N. S. Laser-flash photolysis indicates that internal electron transfer is triggered by proton uptake by Alcaligenes xylosoxidans copper-dependent nitrite reductase. FEBS J. 279, 2174-2181 (2012).

9. Krzemiński, L. et al. Spectroelectrochemical investigation of intramolecular and interfacial electron-transfer rates reveals differences between nitrite reductase at rest and during turnover. J. Am. Chem. Soc. 133, 15085-15093 (2011).

10. Ellis, M. J., Dodd, F. E., Sawers, G., Eady, R. R. \& Hasnain, S. S. Atomic resolution structures of native copper nitrite reductase from Alcaligenes xylosoxidans and the active site mutant Asp92Glu. J. Mol. Biol. 328, 429-438 (2003).

11. Antonyuk, S. V., Strange, R. W., Sawers, G., Eady, R. R. \& Hasnain, S. S. Atomic resolution structures of resting-state, substrate- and productcomplexed $\mathrm{Cu}$-nitrite reductase provide insight into catalytic mechanism. Proc. Natl Acad. Sci. USA 102, 12041-12046 (2005).

12. Godden, J. W. et al. The 2.3 angstrom Xray structure of nitrite reductase from Achromobacter cycloclastes. Science 253, 438-442 (1991).

13. Tocheva, E. I., Rosell, F. I., Mauk, A. G. \& Murphy, M. E. P. Side-on copper-nitrosyl coordination by nitrite reductase. Science 304, 867-870 (2004).

14. Strange, R. W. et al. The substrate binding site in $\mathrm{Cu}$ nitrite reductase and its similarity to Zn carbonic anhydrase. Nat. Struct. Biol 2, 287-292 (1995).

15. Nojiri, M. et al. Structural basis of inter-protein electron transfer for nitrite reduction in denitrification. Nature 462, 117-121 (2009). 
16. Kobayashi, K. \& Tagawa, S. Deligeer \& Suzuki, S. The pH-dependent changes of intramolecular electron transfer on copper-containing nitrite reductase. J. Biochem. 126, 408-412 (1999).

17. Boulanger, M. J., Kukimoto, M., Nishiyama, M., Horinouchi, S. \& Murphy, M. E. Catalytic roles for two water bridged residues (Asp-98 and His-255) in the active site of copper-containing nitrite reductase. J. Biol. Chem. 275, 23957-23964 (2000).

18. Kataoka, K., Furusawa, H., Takagi, K., Yamaguchi, K. \& Suzuki, S. Functional analysis of conserved aspartate and histidine residues located around the type 2 copper site of copper-containing nitrite reductase. J. Biochem. 127, 345-350 (2000).

19. Wijma, H. J., Jeuken, L. J., Verbeet, M. P., Armstrong, F. A. \& Canters, G. W. Protein film voltammetry of copper-containing nitrite reductase reveals reversible inactivation. J. Am. Chem. Soc. 129, 8557-8565 (2007).

20. Hough, M. A., Eady, R. R. \& Hasnain, S. S. Identification of the proton channel to the active site type $2 \mathrm{Cu}$ centre of nitrite reductase: structural and enzymatic properties of His254Phe and Asn90Ser mutants. Biochemistry 47, 13547-13553 (2008).

21. Suzuki, S. et al. Spectroscopic characterization and intramolecular electron transfer processes of native and type $2 \mathrm{Cu}$-depleted nitrite reductases. J. Biol. Inorg. Chem. 2, 265-274 (1997).

22. Farver, O., Eady, R. R., Abraham, Z. H. \& Pecht, I. The intra-molecular electron transfer between the copper sites of nitrite reductase: a comparison with ascorbate oxidase. FEBS Lett. 436, 239-242 (1998).

23. Wijima, H. J., Jeuken, L. J. C., Verbeet, M. P., Armstrong, F. A. \& Canters, G. W. A random-sequential mechanism for nitrite binding and active site reduction in copper-containing nitrite reductase. J. Biol. Chem. 281, 16340-16346 (2006).

24. Boulanger, M. J. \& Murphy, M. E. Directing the mode of nitrite binding to a copper-containing nitrite reductase from Alcaligenes faecalis S-6: Characterization of an active site isoleucine. Protein Sci. 12, 248-256 (2003).

25. Källrot, N., Nilsson, K., Rasmussen, T. \& Ryde, U. Theoretical study of structure of catalytic copper site in nitrite reductase. Int. J. Quant. Chem. 102, 520-541 (2004).

26. Prudêncio, M., Eady, R. R. \& Sawers, G. The blue copper-containing nitrite reductase from Alcaligenes xylosoxidans: cloning of the nirA gene and characterization of the recombinant enzyme. J. Bacteriol. 181, 2323-2329 (1999).

27. Kabsch, W. XDS. Acta Crystallogr. D Biol. Crystallogr. D66, 125-132 (2010).

28. Battye, T. G. G., Kontogiannis, L., Johnson, O., Powell, H. R. \& Leslie, A. G. W. iMOSFLM: a new graphical interface for diffraction-image processing with MOSFLM. Acta Crystallogr. D Biol. Crystallogr. D67, 271-281 (2011).

29. Evans, P. R. Scaling and assessment of data quality. Acta Cryst. D Biol. Crystallogr. D62, 72-82 (2006).

30. Murshudov, G. N., Vagin, A. A. \& Dodson, E. J. Refinement of macromolecular structures by the maximum-likelihood method. Acta Crystallogr. D Biol. Crystallogr. D53, 240-255 (1997).

31. Winn, M. D. et al. Overview of the CCP4 suite and current developments. Acta Crystallogr. D Biol. Crystallogr D67, 235-242 (2011).
32. Emsley, P. \& Cowtan, K. Coot: model-building tools for molecular graphics. Acta Crystallogr. D Biol. Crystallogr. D60, 2126-2132 (2004).

33. Chen, V. B. et al. MolProbity: all-atom structure validation for macromolecular crystallography. Acta Cryst. D Biol. Crystallogr. 66, 12-21 (2010).

34. Abraham, Z. H., Smith, B. E., Howes, B. D., Lowe, D. J. \& Eady, R. R. $\mathrm{pH}$-dependence for binding a single nitrite ion to each type-2 copper centre in the copper-containing nitrite reductase of Alcaligenes xylosoxidans. Biochem. J. 324, 511-516 (1997).

35. Dunn, R. V., Marshall, K. R., Munro, A. W. \& Scrutton, N. S. The pH dependence of kinetic isotope effects in monoamine oxidasse A indicate stabilization of the neutral amine in the enzyme-substrate complex. FEBS $J$. 275, 3850-3858 (2008).

\section{Acknowledgements}

This work was supported by the Biotechnology and Biological Sciences Research Council, UK (grant number BB/G005869/1 to S.S.H. and R.R.E.) and BB/G005850/1 to N.S.S.). S.V.A. acknowledges the support from Wellcome Trust (097826/Z/11/Z). We would like to thank the staff and management of SOLEIL and Diamond for provision of the crystallographic facilities at their synchrotron centres. Use of SOLEIL was part funded by the European Community's Seventh Framework Program (FP7/2007-2013) under BioStruct-X (grant agreement number 283570 and proposals number 2370/5437 to S.V.A. and S.S.H)

\section{Author contributions}

S.S.H., R.R.E. and N.S.S. conceived and designed the project; J.A.H. cloned the mutant N.G.H.L. purified proteins and performed kinetic experiments; S.V.A. crystallized and undertook X-ray data collection, processing, structure determination and refinement; N.G.H.L., S.V.A., R.R.E., N.S.S. and S.S.H. wrote the manuscript.

\section{Additional information}

Acceession codes: Atomic coordinates and structure factors for the reported crystal structures have been deposited in the Protein Data Bank under accession codes $4 \operatorname{csp}(\mathrm{r} 4 \mathrm{cspsf})$ and $4 \operatorname{csz}(\mathrm{r} 4 \mathrm{cszs})$

Competing financial interests: The authors declare no competing financial interests.

Reprints and permission information is available online at http://npg.nature.com/ reprintsandpermissions/

How to cite this article: Leferink, N. G. H. et al. Impact of residues remote from the catalytic centre on enzyme catalysis of copper nitrite reductase. Nat. Commun. 5:4395 doi: 10.1038/ncomms5395 (2014)

This work is licensed under a Creative Commons Attribution 4.0 International License. The images or other third party material in this article are included in the article's Creative Commons license, unless indicated otherwise in the credit line; if the material is not included under the Creative Commons license, users will need to obtain permission from the license holder to reproduce the material. To view a copy of this license, visit http://creativecommons.org/licenses/by/4.0/ 